\title{
Community Structure of Aspergillus flavus and A. parasiticus in Major Almond-Producing Areas of California, United States
}

\author{
Matthias Donner, Department of Plant Pathology, University of California, Davis, Kearney Agricultural Research and Extension Center, \\ Parlier 93648; Paulo S. F. Lichtemberg, Department of Crop Protection, Federal University of Paraná State, Curitiba, PR 80035-050, Brazil; \\ Mark Doster and Adeline Picot, Department of Plant Pathology, University of California, Davis, Kearney Agricultural Research and Extension \\ Center; Peter J. Cotty, Department of Plant Science, University of Arizona, United States Department of Agriculture-Agricultural Research \\ Service, Division of Plant Pathology and Microbiology, Tucson 85721; and Ryan D. Puckett and Themis J. Michailides, Department of Plant \\ Pathology, University of California, Davis, Kearney Agricultural Research and Extension Center
}

\begin{abstract}
Donner, M., Lichtemberg, P. S. F., Doster, M., Picot, A., Cotty, P. J., Puckett, R. D., and Michailides, T. J. 2015. Community structure of Aspergillus flavus and A. parasiticus in major almond-producing areas of California, United States. Plant Dis. 99:1161-1169.

Several nut crops, including almond, pistachio, and walnut, can become contaminated with mycotoxins. Of greatest economic significance are aflatoxins, which are mainly produced by members of Aspergillus section Flavi. The distribution of the two sclerotial-size morphotypes of Aspergillus flavus (i.e., S and L strains) and A. parasiticus, the main species responsible for aflatoxin production among section Flavi, was monitored in the soil of almond orchards in California over a 5-year period from 2007 to 2011, excluding 2009. In total, 4,349 Aspergillus isolates were collected from 28 almond orchards located in the northern, central, and southern Central Valley in California. Overall, A. flavus $\mathrm{L}$ strain was the most frequent, followed by A. parasiticus and A. flavus $\mathrm{S}$ strain. However, variations in the spatial distribution of these three taxa were found between the three regions. Over the 5-year period, higher frequencies of $\mathrm{L}$ strain were more often observed in the southern region (79.9 to $95.1 \%$, depending on year) compared with the northern

region (21.4 to $47.1 \%)$. In the north, A. parasiticus was the most common strain, with frequencies of 28.5 to $61 \%$ for the various years. In addition, the frequency of aflatoxin-producing isolates among $\mathrm{L}$ strains fluctuated from year to year. A significant increase $(P=0.0001)$ was observed from 2008 ( $75 \%$ of the isolates produced aflatoxins) to 2007 (59\%), and a decrease was observed from 2010 (61\%) to 2011 $(53 \%)$. Aflatoxin-producing L strain isolates were significantly more prevalent than atoxigenic isolates in each region during the 5-year survey, except in 2011 in the north, where more isolates were atoxigenic $(56 \%)$ than aflatoxin-producing $(44 \%)$. Our results indicate that the structure of A. flavus and A. parasiticus communities in the soil and the proportion of toxigenic isolates vary across regions and years. Such knowledge may help devise appropriate aflatoxin control strategies, including the use of atoxigenic isolates as biological control agents adapted to the soil environments in each region.
\end{abstract}

Almond (Prunus dulcis L.) is an important and valuable nut crop for the state of California, with a production farm-gate value of $\$ 4.8$ billion in 2012 (USDA-NASS 2011). Each year, approximately $70 \%$ of the total almond production in California is exported, mainly to Western Europe and Pacific Asia (CA-ABC 2013). California tree nuts such as almond, pistachio, and walnut are susceptible to aflatoxin contamination (Bayman et al. 2002; Molyneux et al. 2007). Aflatoxins are important secondary metabolites that are mainly produced in agricultural commodities by the fungi Aspergillus flavus and $A$. parasiticus (CAST 2003). Furthermore, aflatoxins are highly carcinogenic and, therefore, concentrations are regulated in most countries of the world (van Egmond et al. 2007). The maximum level of aflatoxins permitted in ready-to-eat almond in Europe is $10 \mathrm{ng} / \mathrm{g}$ (EU 2010), while the U.S. Food and Drug Administration (FDA) maintains a 20-ng/g action level for all nondairy domestic food (FDA 1996). The low tolerance of the European Union is of serious concern to the exporters of California tree nuts, because aflatoxin levels above the allowed limits can result in significant monetary losses (Molyneux et al. 2007).

The species A. flavus is widely distributed, with high incidences found on aerial and underground crops such as corn, cotton, peanut, and tree nuts in comparison with A. parasiticus (Bayman et al. 2002;

M. Donner and P. S. F. Lichtemberg have contributed equally to the research and preparation of this article.

Corresponding author: T. J. Michailides; E-mail: tjmichailides@ucanr.edu

Accepted for publication 21 November 2014.

http://dx.doi.org/10.1094/PDIS-05-14-0450-RE

(C) 2015 The American Phytopathological Society
Horn and Dorner 2009). The dominant aflatoxin-producing species in agricultural fields is A. flavus, which is divided into two main morphotypes: the $\mathrm{L}$ strain and $\mathrm{S}$ strain. The $\mathrm{L}$ strain is known to produce small to larger sclerotia and exhibit a wide toxigenic range of $B_{1}$ aflatoxin concentration, achieving high levels of $\mathrm{B}_{1}$ in comparison with $\mathrm{B}_{2}$ concentrations. In contrast, the $\mathrm{S}$ strain presents numerous small sclerotia and produces consistently high levels of $\mathrm{B}_{1}$ and $\mathrm{B}_{2}$ aflatoxins (Cotty 1989; Horn and Dorner 2009; Klich 2007). Several surveys indicate that the $S$ strain contributes the greatest to the aflatoxin-producing potential of the fungal communities in few parts of the world (Donner et al. 2009; Jaime-Garcia and Cotty 2010; Probst et al. 2010), and is mainly associated with aflatoxin contamination of corn (Probst et al. 2010) and cotton (Jaime-Garcia and Cotty 2006) but not almond. A. parasiticus strains produce $\mathrm{G}_{1}$ and $\mathrm{G}_{2}$ in addition to the $\mathrm{B}$ aflatoxins (Horn et al. 1996). This species produces generally high concentrations of aflatoxin, and atoxigenic strains are rare (Horn et al. 1996).

Interest in the distribution and variability of aflatoxin-producing strains across the almond-growing areas of California has increased due to recent efforts to reduce aflatoxin contamination by using atoxigenic $A$. flavus isolates, as successfully reported in cottonseed (Cotty 1994b), corn (Abbas et al. 2006), peanut (Dorner et al. 2003), and pistachio (Doster et al. 2014). Given the increasing interest in the use of atoxigenic isolates as potential biological control agents, surveys are needed to better characterize the diversity and distribution patterns of Aspergillus communities in almond orchard soil. In this report, we determined the spatial and temporal distribution of A. flavus (S and L morphotypes) and A. parasiticus isolates in soils of the three main almond-producing areas in the Central Valley of California for 4 of 5 years $(2007,2008,2010$, and 2011). In addition, the aflatoxin-producing potential of the isolates from each region was assessed. 


\section{Materials and Methods}

Survey sites. Soil samples were collected from 28 commercial almond orchards in three regions of the Central Valley during September 2007, 2008, 2010, and 2011. In total, 11 orchards were surveyed in the northern region (Colusa, Glenn, and Butte Counties), 9 orchards in central region (Madera County), and 8 orchards in the southern region (Kern County) (Fig. 1). The Central Valley is located in the interior of the state of California between the coastal range to the west and the Sierra Nevada mountain range to the east. Yearly mean temperatures range from 8.6 to $24.8^{\circ} \mathrm{C}$ across the seasons (CIMIS 2011), with mean precipitation of these surveyed regions of 284 to $469 \mathrm{~mm}$ (with decreasing precipitation from north to south). Average elevation is $36 \mathrm{~m}$ (in the south) to $397 \mathrm{~m}$ (in the north) and the soil $\mathrm{pH}$ ranges from 4.0 to 8.2 (USDA-NRCS 2011).

Soil sampling. Soil samples were obtained from the middle of each orchard by walking along a triangle approximately $100 \mathrm{~m}$ on each side. Three samples were collected per orchard, each composed of 10 subsamples of 4 to $8 \mathrm{~g}$, taken to a depth of $3 \mathrm{~cm}$ at regular intervals on each side of the triangle. All samples were stored in a cold room at $4^{\circ} \mathrm{C}$. The soil samples were then dried at room temperature for 7 days, clumps were broken, and samples were hand mixed for homogenization.

Strain isolation and identification. The density of $A$. flavus and A. parasiticus populations in the soil was quantified by spreading $0.2 \mathrm{~g}$ of ground soil evenly on 10 plates of modified rose bengal agar (Cotty 1994a). Plates were incubated in the dark for 3 days at $31^{\circ} \mathrm{C}$. Colonies were counted and identified by morphological criteria (Klich and Pitt 1988). No more than 25 single-spore isolates were subcultured on Czapek yeast agar (Klich and Pitt 1988) and incubated in the dark for 7 days at $31^{\circ} \mathrm{C}$. A. flavus was designated as $\mathrm{S}$ or L strain based on their colony characteristics and the size of their sclerotia (Cotty 1989). A. parasiticus was characterized by colony and spore morphology (Klich and Pitt 1988). Identifications were confirmed by the color reaction on AFPA (Aspergillus flavus and parasiticus agar) (Pitt et al. 1983). The density of Aspergillus section Flavi in soil was calculated as CFU per gram of soil. The isolates were stored as mycelial plugs with conidia in water vials at $4^{\circ} \mathrm{C}$.

Determination of aflatoxin-producing isolates. The ability of Aspergillus isolates to produce aflatoxins in an artificial medium was used to determine the frequency of aflatoxin-producing strains and to compare the toxigenic potential between regions. Isolates were fermented in Adye and Mateles (A\&M) medium (Mateles and Adye 1965), using $22.4 \mathrm{mM}$ urea as the sole nitrogen source, adjusted to pH 4.7 prior to autoclaving (Cotty and Cardwell 1999). Glass vials $(15 \mathrm{ml})$ containing $5 \mathrm{ml}$ of A\&M media were inoculated with $50 \mu \mathrm{l}$ of a suspension of $2 \times 10^{3}$ conidia/ml. Following incubation (7 days, $31^{\circ} \mathrm{C}$ ), fungal cells were lyzed by adding $3 \mathrm{ml}$ of acetone. After $1 \mathrm{~h}$, $5 \mathrm{ml}$ of water and $3 \mathrm{ml}$ of dichloromethane were added and vial contents were mixed by inverting several times. The dichloromethane phase was allowed to settle for $1 \mathrm{~h}$, removed with a glass pipette, and then filtered $(0.2-\mu \mathrm{m}$ nylon membrane; VWR International, Radnor, PA) into clean 4-ml vials. Extracts were completely evaporated and redissolved in $1 \mathrm{ml}$ of methanol and $1 \mathrm{ml}$ of water before injection into the high-performance liquid chromatography (HPLC) system. Extracts containing high concentrations of aflatoxins were diluted as needed. The mycelia were collected with suction on preweighed Whatman number 4 filter paper, dried in a forced-air oven at $46^{\circ} \mathrm{C}$ for 7 days, and weighed to quantify fungal biomass.

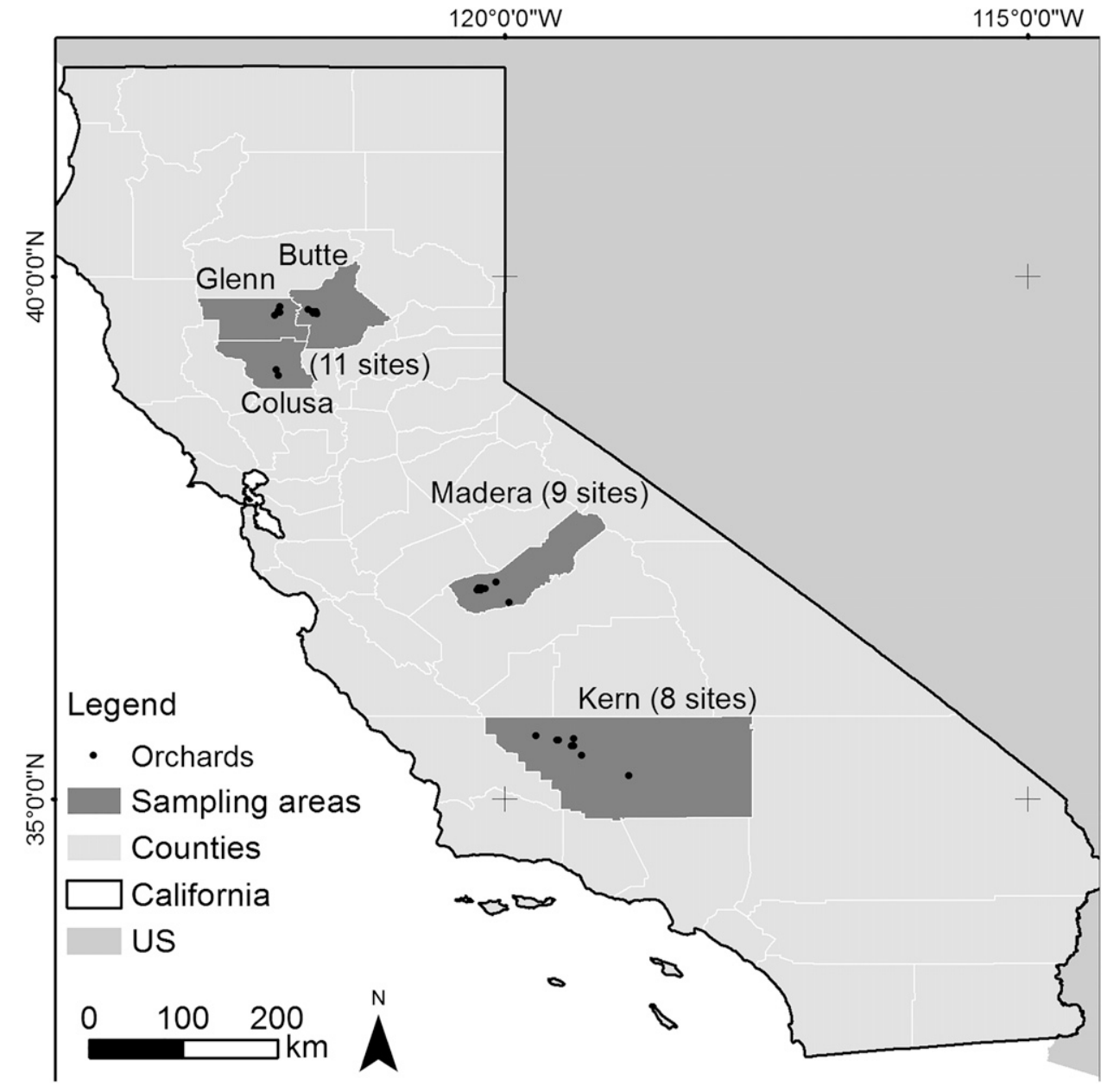

Fig. 1. Map of California showing the five surveyed counties and 28 sampling areas were Aspergillus isolates were collected. 
Aflatoxins were quantified by HPLC (Hewlett Packard 1050) with an isocratic pump, autosampler, and fluorescence detector (Hewlett Packard 1046A). Aflatoxins were separated on a Nova-Pak C18 column (length of $150 \mathrm{~mm}$, inner diameter [i.d.] of $3.9 \mathrm{~mm}$, and particle size of $4 \mu \mathrm{m}$ ) supplied by Waters (Milford, MA), with column temperature set at $25^{\circ} \mathrm{C}$ (CHX650; Pickering Laboratories). The mobile phase was methanol/water $(45: 55, \mathrm{vol} / \mathrm{vol})$, with a flow rate of $0.8 \mathrm{ml}$ $\mathrm{min}^{-1}$. A postcolumn photochemical reactor (Aura Industries, Inc., Staten Island, NY) with a knitted reactor coil ( $0.25 \mathrm{~mm}$ i.d. by $25 \mathrm{~m})$ was used to enhance aflatoxin fluorescence. Light wavelengths of 360 and $440 \mathrm{~nm}$ were used for excitation and emission, respectively. The injection volume was $100 \mu \mathrm{l}$ unless further dilution was necessary for estimating peak area. Limits of detection of aflatoxins were $0.29 \mathrm{ppb}$ for $\mathrm{B}_{1}$ and $\mathrm{G}_{1}, 0.12 \mathrm{ppb}$ for $\mathrm{B}_{2}$, and $0.15 \mathrm{ppb}$ for $\mathrm{G}_{2}$. Aflatoxin concentrations were extrapolated from an eight-point calibration curve from a standard comprised of all four aflatoxins (Supelco Inc., Bellefonte, $\mathrm{Pa}$ ).

Statistical analyses. Analyses were performed using the statistical software $\mathrm{R}$ (version 2.15.1). For each taxon (A. parasiticus and $\mathrm{L}$ and $\mathrm{S}$ strain of $A$. flavus), values of $\mathrm{B}_{1}$ and $\mathrm{G}_{1}$ aflatoxin concentration were analyzed as a function of year and region, using a linear mixed model most appropriated for the presence of random effect (Laird and Ware 1982). Year and region were considered crossed fixed effects while orchard was set as a random effect. Log transformation was used to satisfy model assumptions. Model parameters were estimated by maximum likelihood and mean comparisons were performed using appropriate linear functions while the experimental error rate of the means comparison was corrected by false discovery rate (FDR) criteria (Benjamini and Hochberg 1995). A similar analysis was used for values of CFU.

The generalized linear model was used to estimate the proportion of A. parasiticus, A. flavus $\mathrm{L}$, and A. flavus $\mathrm{S}$ strain, as well as the proportion of aflatoxin-producing (toxigenic) and atoxigenic isolates, as a function of year and region (Nelder and Baker 1972). The quasibinomial model was preferred over the binomial model due to the dispersion of data. Means were compared with FDR.

\section{Results}

Aspergillus populations. The density analysis of Aspergillus section Flavi per gram of soil revealed statistical differences $(P=$ $0.0089)$ between the studied years. By comparison, the year 2011 revealed fewer $\mathrm{CFU}$ (6.1 CFU g ${ }^{-1}$ of soil) than the previous years (Table 1). A significant interaction $(P=0.0092)$ between year and region was also observed. In the northern region, Aspergillus section Flavi density was stable during the whole surveyed period (Table 1). In the central region, reduction was observed in 2011 in relation to the previous years whereas, in the southern region, the CFU counts for 2011 decreased in relation to those in 2010 but were not different from those in 2007 and 2008 (Table 1).

The strain distribution indicates a predominance of $A$. flavus $\mathrm{L}$ strain in $2010(67.7 \%)$ and 2011 (51.2\%) in comparison with A. parasiticus and A. flavus S strains (Table 2). In 2007 and 2008, A. flavus L strain and $A$. parasiticus showed similar distribution among the surveyed orchards in the Central Valley of California (Table 2). The S strain of A. flavus was the clear minority in 2007, 2008, and 2011, sharing with A. parasiticus similar frequency in 2010 (Table 2). Examination of our results also indicates variations in the spatial distribution of these three taxa within regions. The occurrence of $A$. flavus $\mathrm{L}$ strain was always significantly higher than A. parasiticus and A. flavus $\mathrm{S}$ strain in the southern region during all surveyed years, with frequencies of $95.1 \%$ (2007), 85.4\% (2008), $79.9 \%$ (2010), and $87.5 \%$ (2011) (Fig. 2). The frequency of $A$. parasiticus was significantly higher in the northern region in $2007(58.3 \%, P=0.0064)$ but similar to $A$. flavus L strain in $2008(P=0.2767)$ and $2011(P=0.3657)$ (Fig. 2). In the central region, the distribution was balanced, with similar recovery of $\mathrm{L}$ strain and $A$. parasiticus, except in 2010, when the frequency of $\mathrm{L}$ strain isolates was significantly higher than $A$. parasiticus (Fig. 2). The $\mathrm{S}$ strain was the least common taxon in the central region, with a range from 0.6 to $3.1 \%$, and was most commonly isolated in the north, with a range from 7 to $24.5 \%$ (Fig. 2). No significant differences in the frequency of the $\mathrm{L}$ strains between the years were observed $(P=$ $0.2044)$, unlike $A$. parasiticus $(P=4.04 \mathrm{e}-6)$, which showed increased frequency from 2010 to 2011 , and $\mathrm{S}$ strain $(P=0.0324)$, with increased frequency from 2008 to 2010 and remaining stable in 2011 (Table 1).

Frequency of aflatoxin-producing isolates. For all orchards and for every year of the survey, atoxigenic isolates (isolates unable to produce detectable levels of aflatoxin under optimal conditions for production) were only found for A. flavus L strain isolates (data not shown). Among the $\mathrm{L}$ strain populations, atoxigenic isolates were always outnumbered by toxigenic strains, as observed in $2007(P=$ 6.53e-6), $2008(P=2 \mathrm{e}-2), 2010(P=1.8 \mathrm{e}-7)$, and $2011(P=$ 0.0342 ) (Table 2). The prevalence of toxigenic strains was observed within each separated region during the whole survey period (Fig. 3), except in the northern region for the years $2010(P=0.395$; Fig. 3C) and $2011(P=0.055$; Fig. 3D), where similar frequencies were observed. The frequency of toxigenic (aflatoxin-producing) $\mathrm{L}$ strain isolates varied from year to year $(P=0.0001)$, with a significant increase from $2007(64.3 \%)$ to $2008(81.6 \%)$, followed by a reduction in $2010(61.3 \%)$ and stability in 2011 (53.4\%) (Table 2).

The production of the principle aflatoxin of concern, the $\mathrm{B}_{1}$ toxin, by $\mathrm{L}$ strain isolates was compared for the years in the survey, and significant differences were found $(P=0.001)$. The mean concentration of $\mathrm{B}_{1}$ toxin increased from 6.3 to $67.7 \mu \mathrm{g} \mathrm{g}^{-1}$ for 2007 and 2010 isolates, respectively (Table 3 ). In 2011, the mean concentration of $B_{1}$ aflatoxin was $11.8 \mu \mathrm{g} \mathrm{g}^{-1}$, similar to the values observed in 2007 and 2008 (Table 3 ). The production of $B_{1}$ aflatoxin by the $L$ strain taxon within region increased in 2010 , and returned to a decrease in 2011 for similar levels found in 2007 in the northern, central, and southern regions of Central Valley (Table 3). Differences for $\mathrm{B}_{1}$ aflatoxin produced by the $\mathrm{S}$ strain isolates were only observed in the central region from 2010 to 2011 (8.8 to $99.7 \mu \mathrm{g} \mathrm{g}^{-1}, P=$ 0.0212) (Table 4). Concentrations of $B_{1}$ aflatoxin produced by the $\mathrm{S}$ strain was stable in northern (105.3 to $\left.42.1 \mu \mathrm{g} \mathrm{g}^{-1}, P=0.0772\right)$ and southern (87.5 to $\left.65.6 \mu \mathrm{g} \mathrm{g}^{-1}, P=0.638\right)$ regions of California (Table 4).

Isolates of A. parasiticus collected in 2010 and 2011 were assessed for their ability to produce both $\mathrm{B}_{1}$ and $\mathrm{G}_{1}$ aflatoxins on artificial media. In the northern region, both aflatoxin types had significantly lower concentrations $\left(P=0.0128\right.$ for $\mathrm{B}_{1}$ and $P=3 \mathrm{e}-9$ for $\left.\mathrm{G}_{1}\right)$ in 2010 compared with 2011 (Table 5). In the central and southern regions, $B_{1}$ and $G_{1}$ aflatoxin concentrations showed no differences between surveyed years (Table 5).

Table 1. Density of Aspergillus section Flavi in soils of almond orchards from three regions of the Central Valley in California during 4 years

\begin{tabular}{|c|c|c|c|c|c|c|c|c|c|}
\hline \multirow[b]{3}{*}{ Year } & \multicolumn{9}{|c|}{ Density $\left(\text { CFU } \mathrm{g}^{-1} \text { of soil) }\right)^{\mathrm{z}}$} \\
\hline & \multicolumn{3}{|c|}{ Total } & \multicolumn{2}{|c|}{ North } & \multicolumn{2}{|c|}{ Central } & \multicolumn{2}{|c|}{ South } \\
\hline & $n$ & Mean & CI95\% ${ }^{\mathrm{c}}$ & Mean & CI95\% & Mean & CI95\% & Mean & CI95\% \\
\hline 2007 & 765 & $12.1 \mathrm{a}$ & $7.7-19.1$ & $7.8 \mathrm{a}$ & $3.8-15.9$ & $18.2 \mathrm{a}$ & $8.2-40.2$ & $12.7 \mathrm{ab}$ & $5.4-29.4$ \\
\hline 2008 & 306 & $13.2 \mathrm{a}$ & $8.3-21.0$ & $6.9 \mathrm{a}$ & $3.3-14.1$ & $31.6 \mathrm{a}$ & $14.2-70.0$ & $10.6 \mathrm{ab}$ & $4.3-26.1$ \\
\hline 2010 & 1,334 & $16.8 \mathrm{a}$ & $10.6-26.5$ & $7.5 \mathrm{a}$ & $3.6-15.3$ & $21.0 \mathrm{a}$ & $9.5-46.5$ & $30.3 \mathrm{a}$ & $13.0-70.6$ \\
\hline 2011 & 1,268 & $6.1 \mathrm{~b}$ & $3.9-9.7$ & $8.7 \mathrm{a}$ & $4.2-17.7$ & $3.8 \mathrm{~b}$ & $1.7-8.3$ & $7.1 \mathrm{~b}$ & $3.0-16.4$ \\
\hline
\end{tabular}

${ }^{\mathrm{z}}$ Density measured by the CFU per gram of soil. Means not sharing a common letter are significantly different according to false discovery rate test $(\alpha=5 \%)$. CFU were log transformed prior analysis. CI95\% = confidence interval for $95 \%$. 
In 2010, the comparison of $\mathrm{B}_{1}$ aflatoxin concentrations produced by the three taxa revealed significant differences $(P=0.0023)$. The A. parasiticus produced higher mean concentrations (107.6 $\mu \mathrm{g} \mathrm{g}^{-1}$, $P=0.0199)$ than the $\mathrm{S}$ strain $\left(38 \mu \mathrm{g} \mathrm{g}^{-1}\right)$, and concentrations similar
$(P=0.2248)$ to those produced by the $\mathrm{L}$ strain $\left(67.7 \mu \mathrm{g} \mathrm{g}^{-1}\right)$ (Table 6). In 2011, the A. parasiticus and S strain concentrations were similar $(P=0.9746)$, producing 90 and $65.1 \mu \mathrm{g} \mathrm{g}^{-1}$, respectively (Table 6).

Table 2. Isolate strain and toxigenicity frequency in Aspergillus flavus and A. parasiticus populations from almond orchard soils in Central Valley California ${ }^{\mathrm{y}}$

\begin{tabular}{|c|c|c|c|c|c|c|c|}
\hline \multirow[b]{2}{*}{ Year } & \multicolumn{4}{|c|}{ Strain frequency $(\%)$} & \multicolumn{3}{|c|}{ Toxigenicity frequency $(\%)^{\mathbf{z}}$} \\
\hline & $n$ & L strain & S strain & A. parasiticus & $n$ & Toxigenic & Atoxigenic \\
\hline 2007 & 765 & 47.7 a A & $10.3 \mathrm{ab} \mathrm{B}$ & $42.0 \mathrm{a} \mathrm{A}$ & 258 & $64.3 \mathrm{~b} \mathrm{~A}$ & 35.7 a B \\
\hline 2008 & 306 & 54.2 a A & $2.9 \mathrm{~b} \mathrm{~B}$ & $42.8 \mathrm{a} \mathrm{A}$ & 277 & 81.6 a A & $18.4 \mathrm{~b} \mathrm{~B}$ \\
\hline 2010 & 1334 & 67.7 a A & 15.9 a B & $16.4 \mathrm{~b} \mathrm{~B}$ & 359 & $61.3 \mathrm{~b} \mathrm{~A}$ & 38.7 a B \\
\hline 2011 & 1268 & 51.2 a A & $12.1 \mathrm{ab} \mathrm{C}$ & 36.8 a B & 262 & $53.4 \mathrm{~b} \mathrm{~A}$ & 46.6 a B \\
\hline
\end{tabular}

${ }^{\mathrm{y}}$ Means not sharing a common letter are significantly different according to false discovery rate test $(\alpha=5 \%)$. Lowercase letters compare frequencies among year (vertical) and uppercase letters compare frequencies between strain and toxigenicity types (horizontal).

${ }^{\mathrm{z}}$ The toxigenic frequency evaluates only A. flavus L strain.

A -2007

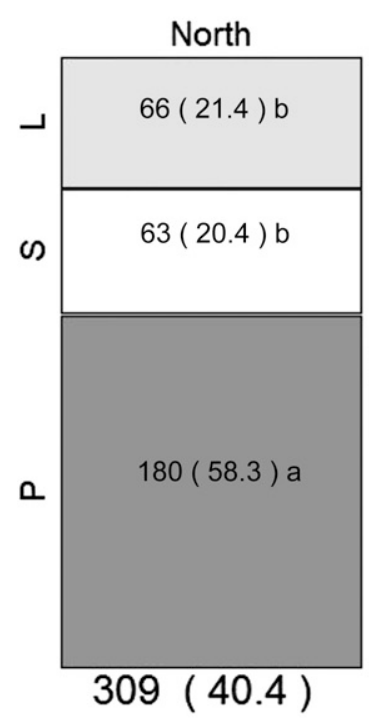

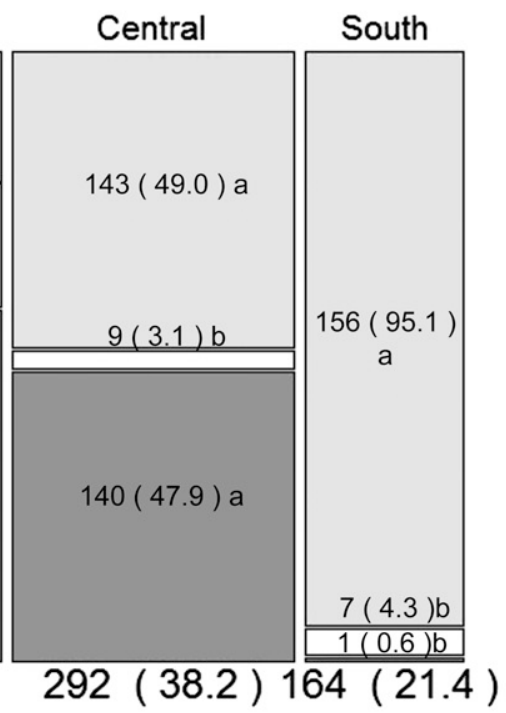

C -2010

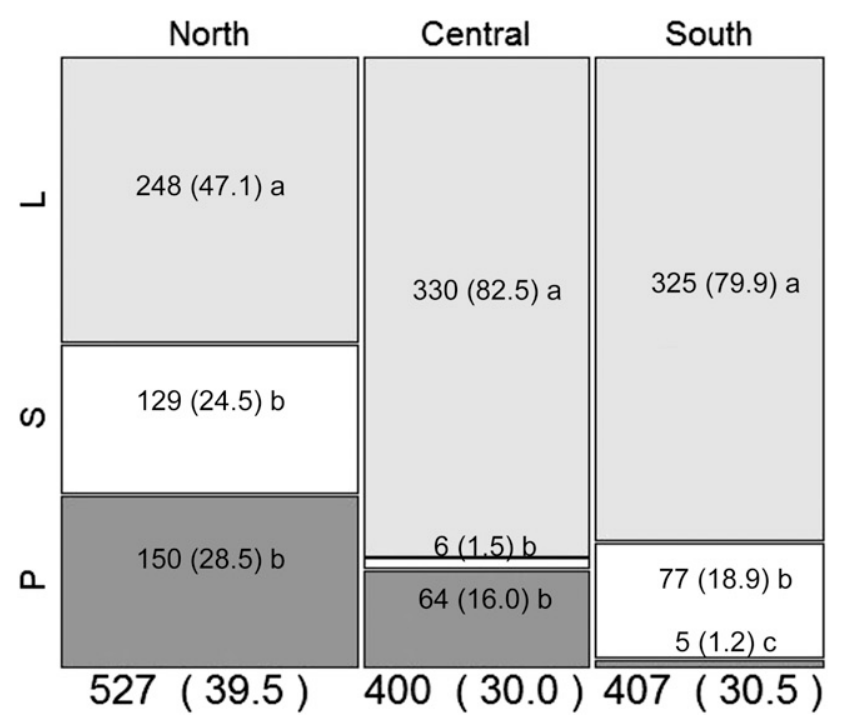

B -2008
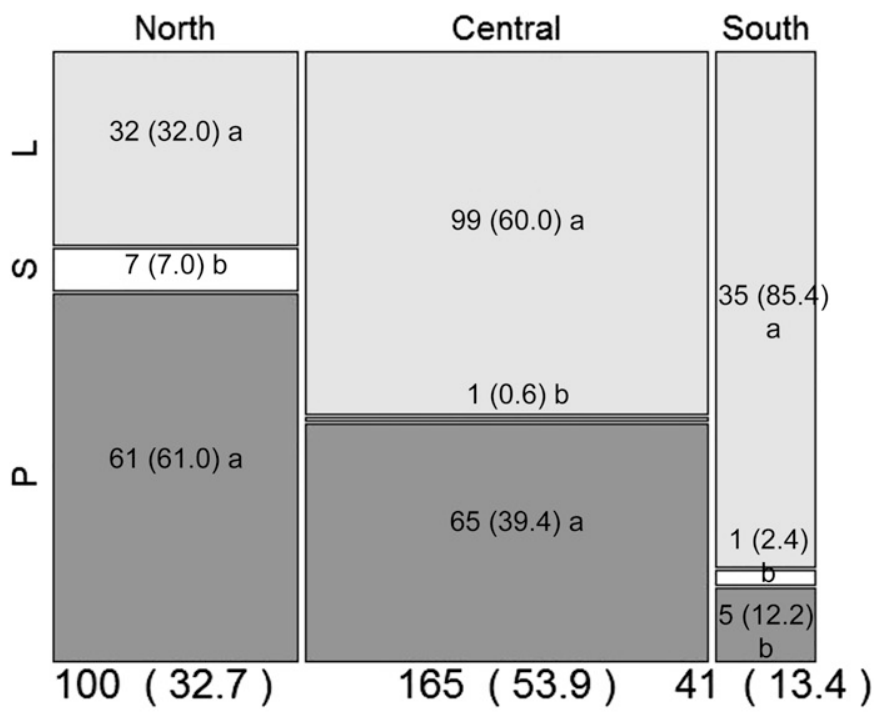

D -2011

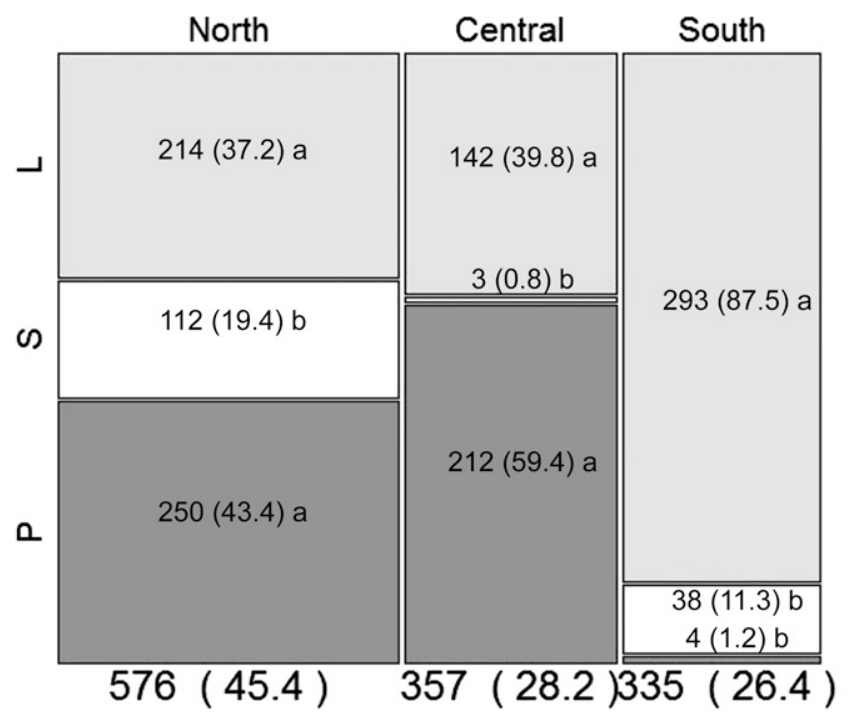

Fig. 2. Frequency distribution of Aspergillus flavus $\mathrm{L}$ strain $(\mathrm{L}), A$. flavus $\mathrm{S}$ strain $(\mathrm{S})$, and $A$. parasiticus $(\mathrm{P})$ collected in soils of three major almond-growing regions in $\mathbf{A}, 2007$; $\mathbf{B}$, 2008; C, 2010; and D, 2011. Histogram width is proportional to the sample size. Sample size is followed by its percentage in between brackets. Means not sharing a common letter are significantly different $(\alpha=0.05)$ according to false discovery rate. 

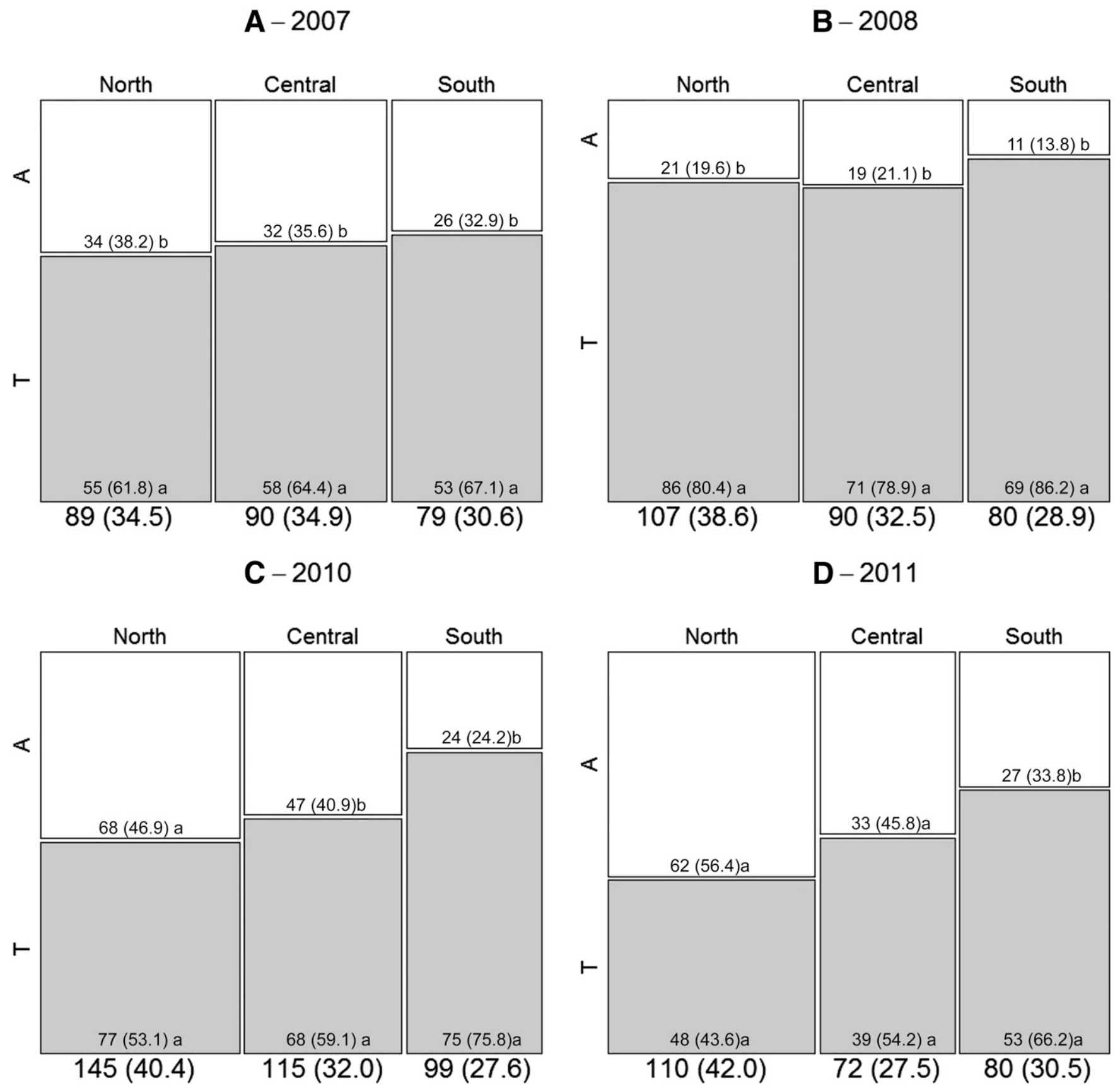

Fig. 3. Frequency distribution of atoxigenic $(A)$ and aflatoxin-producing isolates $(T)$ of $A$ spergillus flavus $L$ strain collected in soils of three major almond-growing regions in $A$, 2007: B, 2008; C, 2010; and D, 2011. Histogram width is proportional to the sample size. Means not sharing a common letter are significantly different $(\alpha=0.05)$ according to false discovery rate.

Table 3. Levels of $\mathrm{B}_{1}$ aflatoxin produced by isolates of Aspergillus flavus $\mathrm{L}$ strain, collected from three regions of the Central Valley in California during 4 years

\begin{tabular}{|c|c|c|c|c|c|c|c|c|c|}
\hline \multirow[b]{3}{*}{ Year } & \multicolumn{9}{|c|}{ Aflatoxin $B_{1}\left(\mu g^{-1}\right)^{z}$} \\
\hline & \multicolumn{3}{|c|}{ Total } & \multicolumn{2}{|c|}{ North } & \multicolumn{2}{|c|}{ Central } & \multicolumn{2}{|c|}{ South } \\
\hline & $n$ & Mean & $\mathrm{CI} 95 \% \mathrm{c}$ & Mean & CI95\% & Mean & CI95\% & Mean & $\mathrm{Cl95 \%}$ \\
\hline 2007 & 166 & $6.3 \mathrm{bc}$ & $4.6-8.6$ & $10.2 \mathrm{~b}$ & $6.0-17.6$ & $3.9 \mathrm{~b}$ & $2.3-6.1$ & $6.2 \mathrm{c}$ & $3.6-10.7$ \\
\hline 2008 & 236 & $9.0 \mathrm{~b}$ & $6.9-11.7$ & $11.4 \mathrm{~b}$ & $7.4-17.6$ & $9.4 \mathrm{~b}$ & $6.0-14.7$ & $6.9 \mathrm{bc}$ & $4.3-11.0$ \\
\hline 2010 & 143 & $67.7 \mathrm{a}$ & $52.6-103.2$ & $86.5 \mathrm{a}$ & $46.0-162.5$ & $95.4 \mathrm{a}$ & $53.3-171.0$ & $48.6 \mathrm{a}$ & $28.5-82.8$ \\
\hline 2011 & 140 & $11.7 \mathrm{~b}$ & $8.36-16.51$ & $11.2 \mathrm{~b}$ & $6.3-20.0$ & $8.8 \mathrm{~b}$ & $4.6-16.6$ & $16.4 \mathrm{~b}$ & $9.5-28.4$ \\
\hline
\end{tabular}

${ }^{\mathrm{z}}$ Aflatoxin concentrations are in micrograms of aflatoxin $\mathrm{B}_{1}$ per gram of mycelium. Only aflatoxin-producing isolates were included. Means not sharing a common letter are significantly different according to false discovery rate test $(\alpha=5 \%)$. Data were log transformed prior analysis. CI95\% $=$ confidence interval for $95 \%$. 


\section{Discussion}

Results of the current study indicate that the L strain morphotype of A. flavus is the most common member of section Flavi in soils of almond orchards in California. In addition, two high aflatoxin producers, $A$. parasiticus and $A$. flavus $\mathrm{S}$ strain, are found with varying frequencies across much of the production area. The population structure varied spatially and temporally, which was consistent with previous studies performed on other crops (Bayman and Cotty 1991; Jaime-Garcia and Cotty 2006, 2010). Certain distribution patterns were identified regarding the three strains in this study. In most of the years, except 2010, A. parasiticus isolates were commonly found in the northern region, whereas isolates of A. flavus L strain were most frequently isolated in the south, and very often found in the central region in balanced frequencies with $A$. parasiticus (Fig. 2). These variable distributions may result from differences in mean temperature (Horn and Dorner 1998), changes in irrigation patterns by some growers, and soil type or cropping system (Jaime-Garcia and Cotty 2010). A few decades ago, A. flavus frequencies were correlated to differences in temperatures between the southern (warmer) and northern (cooler) Central Valley almond orchards (Purcell et al. 1980). In the same study, Purcell and associates (1980) had demonstrated that $A$. flavus isolates were most frequently found in almond kernels and hulls collected in warmer regions. The implication of this distribution is that almond produced in the northern region may be exposed to different pathogens associated with contamination than almond produced in the southern region, and aflatoxin management procedures may need to take these differences into consideration.

Heat and drought can influence the structures of Aspergillus section Flavi populations (Cotty and Jaime-Garcia 2007; Horn and Dorner 1999), and this may explain some of the temporal and regional variability observed in the current study. According to the Department of Water Resources, California experienced three consecutive dry years from 2007 until 2009 (CDWR 2010), and changes in the A. flavus and A. parasiticus communities may have been driven, in part, by the prolonged drought. Almond growers irrigate their almond regularly during the summer. Therefore, the drought might not have much effect on Aspergillus fungi, which are mainly active during the summer. However, the drought may have an effect on the population colonization and survival on debris during the winter because, with no rain, it takes longer for the debris to degrade than with frequent winter rainfall.

Variability of toxigenicity of A. flavus isolates within fields (Bayman and Cotty 1993; Cotty 1989), between proximate fields (Cotty 1997), and across regions (Cotty et al. 1994; Mahoney and Rodriguez
1996) often has been reported for other crops. Studies in Argentina (Vaamonde et al. 2003) and Iran (Razzaghi-Abyaneh et al. 2006) revealed that less than $30 \%$ of the A. flavus isolates produced aflatoxin, while the majority ( $88 \%$ ) of A. flavus isolates from soils in the southern United States were aflatoxin producers (Cotty 1997; Horn and Dorner 1999). In California, the percentages of $A$. flavus $\mathrm{L}$ strain isolates producing aflatoxins were 43 and $47 \%$ for isolates from pistachio and fig orchards, respectively (Doster and Michailides 1994b; Doster et al. 1996). The relative distribution of aflatoxin-producing and atoxigenic isolates may be influenced by many factors, including plant species present, soil composition, cropping system, crop management, and environmental conditions such as rainfall and temperature (Horn et al. 1995; Zablotowicz et al. 2007).

The current study shows a prevalence of toxigenic isolates for all surveyed years and regions, with some exception in northern region in 2010 and 2011. However, the incidence of toxigenic A. flavus L strains collected in 2008 was significantly greater than in the other years and, consequently, the proportion of atoxigenic isolates in 2010 and 2011 decreased. These results are in accordance with surveys conducted for peanut-, cotton-, and corn-growing regions which revealed geographic differences in production of aflatoxin $\mathrm{B}_{1}$ by A. flavus (Cotty 1997; Donner et al. 2009; Horn and Dorner 1999).

Soil serves as a reservoir for A. flavus and A. parasiticus, where the fungus benefits from diverse organic matter, including plant debris (Abbas et al. 2008; Doster and Michailides 1994a; Jaime-Garcia and Cotty 2004). Densities of Aspergillus section Flavi propagules in almond orchard soils were relatively low and constant among the years. In the last surveyed year, a decrease from 16.8 to 6.1 $\mathrm{CFU} \mathrm{^{-1 }}$ of soil was observed. In California, even lower densities were observed in soils of fig orchards (Doster et al. 1996) while slightly higher densities occurred in soil of pistachio orchards (Doster and Michailides 1994b). In other cropping systems, much higher densities of Aspergillus section Flavi have been observed. Soil populations of A.flavus are generally higher for corn grown in the United States, with CFU ranging from 200 to 300,000 CFU (Abbas et al. 2004, 2009; Zablotowicz et al. 2007). In cotton and sorghum systems, lower rates of propagules occur, although the rates are still much higher than in almond soils (Abbas et al. 2009; Donner et al. 2009; JaimeGarcia and Cotty 2010). Organic matter such as decaying plant residue has a large influence on A. flavus propagule counts in soils (JaimeGarcia and Cotty 2006, 2010, Zablotowicz et al. 2007). Crop rotation can have an influence on the quantity of $A$. flavus in the soil and on the structure of A. flavus communities (Jaime-Garcia and Cotty

Table 4. Levels of $\mathrm{B}_{1}$ aflatoxin produced by isolates of Aspergillus flavus strain, collected from three regions of the Central Valley in California during 4 years

\begin{tabular}{|c|c|c|c|c|c|c|c|c|c|}
\hline \multirow[b]{3}{*}{ Year } & \multicolumn{9}{|c|}{ Aflatoxin $B_{1}\left(\mu g^{-1}\right)^{z}$} \\
\hline & \multicolumn{3}{|c|}{ North } & \multicolumn{3}{|c|}{ Central } & \multicolumn{3}{|c|}{ South } \\
\hline & $n$ & Mean & CI95\% & $n$ & Mean & CI95\% & $n$ & Mean & CI95\% \\
\hline 2007 & 18 & $105.3 \mathrm{a}$ & $49.5-224.0$ & 4 & $8.8 \mathrm{~b}$ & $1.8-43.5$ & 16 & $87.5 \mathrm{a}$ & $39.9-195.0$ \\
\hline 2011 & 19 & $42.1 \mathrm{a}$ & $20.2-87.9$ & 5 & $99.7 \mathrm{a}$ & $23.8-418.0$ & 12 & $65.6 \mathrm{a}$ & $26.0-165.4$ \\
\hline
\end{tabular}

${ }_{\mathrm{z}}$ Aflatoxin concentrations are in micrograms of aflatoxin $\mathrm{B}_{1}$ per gram of mycelium. Only aflatoxin-producing isolates were included. Means not sharing a common letter are significantly different according to false discovery rate test $(\alpha=5 \%)$. Data were log transformed prior analysis. CI95\% $=$ confidence interval for $95 \%$.

Table 5. Production of $\mathrm{B}_{1}$ and $\mathrm{G}_{1}$ aflatoxins by isolates of Aspergillus parasiticus ${ }^{\mathrm{y}}$

\begin{tabular}{|c|c|c|c|c|c|c|c|c|c|c|}
\hline \multirow[b]{2}{*}{ Year } & \multirow[b]{2}{*}{ Mycotoxin } & \multicolumn{3}{|c|}{ North } & \multicolumn{3}{|c|}{ Central } & \multicolumn{3}{|c|}{ South } \\
\hline & & $n^{\mathrm{z}}$ & Mean & CI95\% & $n$ & Mean & CI95\% & $n$ & Mean & CI95\% \\
\hline 2010 & $\mathrm{~B}_{1}\left(\mu \mathrm{g} \mathrm{g}^{-1}\right)$ & 19 & $343.5 \mathrm{a}$ & $154.0-766.0$ & 17 & $138.0 \mathrm{a}$ & $58.8-324.0$ & 3 & $51.9 \mathrm{a}$ & $7.7-350.0$ \\
\hline 2011 & & 21 & $109.8 \mathrm{~b}$ & $53.3-226.0$ & 12 & $123.0 \mathrm{a}$ & $47.5-320.0$ & 1 & $53.8 \mathrm{a}$ & $1.9-1469.5$ \\
\hline 2010 & $\mathrm{G}_{1}\left(\mu \mathrm{g} \mathrm{g}^{-1}\right)$ & 19 & $385.9 \mathrm{a}$ & $194.0-769.0$ & 17 & $85.4 \mathrm{a}$ & $41-178.0$ & 3 & $69.9 \mathrm{a}$ & $13.5-361.0$ \\
\hline 2011 & & 21 & $32.8 \mathrm{~b}$ & $17.6-61.0$ & 12 & $124.2 \mathrm{a}$ & $54.7-282.0$ & 1 & $48.1 \mathrm{a}$ & $2.8-826.8$ \\
\hline
\end{tabular}

$\mathrm{y}$ Aflatoxin concentration values were log transformed prior to statistical analysis. Means not sharing a common letter are significantly different according to false discovery rate test $(\alpha=0.05)$. CI95\% = mean $95 \%$ confidence interval.

${ }^{\mathrm{z}}$ Number of toxigenic isolates. Only aflatoxin-producing isolates were included for the calculation of the amount of aflatoxins. 
2010). Rotations with corn as the previous crop have been shown to increase quantities of total A. flavus in the soil more than rotations with either cotton or sorghum as previous crops (Jaime-Garcia and Cotty 2010). This is most probably because corn debris that can be contaminated with A. flavus are left on the soil after harvest (Jaime-Garcia and Cotty 2010). Almond nuts, by comparison, are perennial crops and no residuals are left on the soil after harvest. This may explain the relatively lower and constant frequencies of the fungus in the soil of almond orchards over time compared with maize fields.

A. parasiticus was isolated with greater frequency in the northern Central Valley and at lower frequencies in the southern end of the valley. However, A. parasiticus was difficult to isolate from the soils obtained in the central portion of the Central Valley. Doster and Michailides (1994a), Doster and associates (1996), and D. Sneedse and T. J. Michailides (unpublished) have previously associated A. parasiticus with pistachio, walnut, and fig in California. Densities of A. parasiticus in fig orchard soils in the central region were very similar to those we found in our current study for almond soils of the same region (Doster et al. 1996) However, the density of A. parasiticus was greater than A. flavus for the fig orchards. Additionally, a survey of Aspergillus spp. in soil of walnut orchards revealed high incidences of $A$. parasiticus in the north and decreasing frequencies along a transect from north to south (D. Sneedse, and T. J. Michailides, unpublished). For all years of the almond study, incidences of A. parasiticus in the southern region of the Central Valley were low (less than 12.2\%) in the southern Central Valley (Fig. 1). Low frequencies of A. parasiticus occurred in cotton-growing areas of the southwest United States (Cotty 1997) as well as in Texas and Israel (Joffe 1969; Lisker et al. 1993; Schroeder and Boller 1973). These low frequencies may be a result of the warmth and low precipitation of these southern production areas. Low rates of $A$. parasiticus were also reported in soils under 11 different cropping regimens in Missouri (Angle et al. 1982), as well as in corn and peanut fields of southwestern Georgia (Horn and Dorner 1998; Horn et al. 1995).

Survey on the almond nut's mycoflora has shown that A. parasiticus is less common than A. flavus (Bayman et al. 2002). A. parasiticus has been identified as an economic problem for peanut growers, in spite of not being a factor for other crops (Diener et al. 1987; Klich 2007). In the current study, A. parasiticus isolates consistently produced higher concentrations of aflatoxins (which included B and $\mathrm{G}$ aflatoxins) than seen in other studies (Cardwell and Cotty 2002; Donner et al. 2009; Doster et al. 1996). This, combined with the current results for the distribution of $A$. parasiticus in California almond orchards, indicates that A. parasiticus is a potentially important causal agent of aflatoxin contamination for almond in the northern region.

The importance of the A. flavus S strain as an aflatoxin producer in certain crops is well known (Cotty 1989; Jaime-Garcia and Cotty 2006; Probst et al. 2010). The S strain is resident in California and was previously observed in fig and pistachio (Doster and Michailides 1994b; Doster et al. 1996). In crops and regions where the $S$ strain is more closely associated with severe aflatoxin contamination, the $\mathrm{S}$

Table 6. Mean $\mathrm{B}_{1}$ aflatoxin comparisons for Aspergillus section Flavi isolates collected in 2010 and 2011

\begin{tabular}{lcrcc}
\hline & & & \multicolumn{2}{c}{$\mathbf{B}_{\mathbf{1}} \boldsymbol{\mu g} \mathbf{g}^{-\mathbf{1}}$} \\
\cline { 3 - 5 } Strain & Year & $\boldsymbol{n}^{\mathbf{z}}$ & Mean & CI95\% \\
\hline L strain & 2010 & 143 & $67.7 \mathrm{ab}$ & $53.8-85.2$ \\
S strain & & 38 & $38.0 \mathrm{~b}$ & $22.0-65.7$ \\
A. parasiticus & & 39 & $107.6 \mathrm{a}$ & $58.6-197.3$ \\
L strain & 2011 & 140 & $11.8 \mathrm{~b}$ & $8.5-16.1$ \\
S strain & & 36 & $65.1 \mathrm{a}$ & $31.6-134.0$ \\
A. parasiticus & & 34 & $90.0 \mathrm{a}$ & $23.9-338.3$ \\
\hline
\end{tabular}

y Aflatoxin concentration values were log transformed prior to statistical analysis. Means not sharing a common letter are significantly different according to false discovery rate test $(\alpha=0.05)$. CI95\% $=$ mean $95 \%$ confidence interval.

${ }^{\mathrm{z}}$ Number of toxigenic isolates. Only aflatoxin-producing isolates were included for the calculation the amount of aflatoxins. strain populations are substantially greater than those found in the almond soils in the current study. For example, in late summer during cotton boll formation, the incidence of S strain was over $60 \%$ in the desert regions of Arizona (Orum et al. 1997) and was 34\% in soils previously cropped with cotton in southern Texas (Jaime-Garcia and Cotty 2010). The role of the S strain in contaminating almond with aflatoxin is not clear in California. However, the aflatoxinproducing $\mathrm{S}$ strain is resident in the almond orchard soils of California and is generally characterized by greater toxigenic potential than L strains.

Populations composed of highly toxigenic fungal communities are more prevalent in specific geographic areas (Cotty 1997; Cotty et al. 2007; Horn and Dorner 1998; Horn et al. 1995). For example, S strain isolates are more abundant in hot and dry regions; therefore, high incidences are found in western and central Arizona and Texas (Cotty 1997; Jaime-Garcia and Cotty 2006; Orum et al. 1999). Furthermore, the proportion of S strain in A. flavus communities can increase with soil temperature. Therefore, crops such as cotton and sorghum, which are predominately harvested in the southern regions, favor the S strain (Jaime-Garcia and Cotty 2010). In West Africa, a unique $\mathrm{S}$ strain, which is morphologically equivalent to the $\mathrm{S}$ strain from North America but capable of producing both B and G aflatoxins, was found in hot, dry regions near the Sahara (Cardwell and Cotty 2002; Donner et al. 2009). In California, the current study indicated that $\mathrm{S}$ strain morphotypes were present in all regions, with incidences ranging from 3 to $16 \%$. However, the data indicate a patchy distribution, with increased incidences in the northern and southern regions and generally low frequencies in the central region. Similar frequency patterns of $\mathrm{S}$ strain have also been reported for several regions of the United States (Bigelow et al. 2000; Cotty 1997; Horn and Dorner 1998, 1999; Jaime-Garcia and Cotty 2006; Orum et al. 1999). Factors which influence the occurrence and distribution of $\mathrm{S}$ strains in California are not clear. Although crop rotation (JaimeGarcia and Cotty 2010) and elevation (Bigelow et al. 2000) can affect the $\mathrm{S}$ strain population, these do not apply to almond soils in the Central Valley of California. Jaime-Garcia and Cotty (2006) indicated that the incidences of the $S$ strain were positively correlated with the clay content in the soil. The soils of the northern California region contain a relatively high clay content of 25 to $51 \%$ (KAC 2012), which might be sufficient to enhance the competitiveness of the $S$ strain in that region.

Several Aspergillus spp. disperse from soil to crops which they subsequently infect under suitable conditions (Abbas et al. 2008; Cotty and Jaime-Garcia 2007; Horn 2007). Aflatoxin producers are among these species, and populations of aflatoxin-producing $A$. fla$v u s$ in soils increase the risk of aflatoxin contamination in almond nuts. Applications of native atoxigenic A. flavus isolates on agricultural soils have been used successfully to control aflatoxin contamination (Atehnkeng et al. 2008; Cotty 1994b; Dorner et al. 2003; Doster et al. 2014). These atoxigenic A. flavus include two commercial biocontrol products, AF36 and Aflaguard, both of which have U.S. Environmental Protection Agency pesticide registrations and which have been used to limit aflatoxin contamination in commercial maize, peanut, cottonseed, and pistachio (Cotty 1994b; Cotty et al. 1994; Doster et al. 2014). In addition to providing insight into the community structure of section Flavi in California almond soils, our survey assists the process of selecting atoxigenic, A. flavus L-strain candidates for further evaluation as potential biocontrol agents. A genetic population study of the atoxigenic isolates found in this study is currently underway to determine whether some isolates are repeatedly identified across regions and years and, therefore, well adapted to the environment. These isolates may be promising candidates for further evaluation as biocontrol agents in California almond orchards to reduce aflatoxin contamination.

\section{Acknowledgments}

We thank D. Felts, L. Boeckler, D. Morgan, H. Eveillard, and E. Mondini for technical assistance. This material is based upon work supported by the Almond Board of California and a Discovery Grant of the University of California. 


\section{Literature Cited}

Abbas, H. K., Accinelli, C., Zablotowicz, R. M., Abel, C. A., Bruns, H. A., Dong, Y., and Shier, W. T. 2008. Dynamics of mycotoxin and Aspergillus flavus levels in aging $\mathrm{Bt}$ and non-Bt corn residues under Mississippi no-till conditions. J. Agric. Food Chem. 56:7578-7585.

Abbas, H. K., Wilkinson, J. R., Zablotowicz, R. M., Accinelli, C., Abel, C. A., Bruns, H. A., and Weaver, M. A. 2009. Ecology of Aspergillus flavus, regulation of aflatoxin production, and management strategies to reduce aflatoxin contamination of corn. Toxin Rev. 28:142-153.

Abbas, H. K., Zablotowicz, R. M., Bruns, H. A., and Abel, C. A. 2006. Biocontrol of aflatoxin in corn by inoculation with non-aflatoxigenic Aspergillus flavus isolates. Biocontrol Sci. Technol. 16:437-449.

Abbas, H. K., Zablotowicz, R. M., and Locke, M. A. 2004. Spatial variability of Aspergillus flavus soil populations under different crops and corn grain colonization and aflatoxins. Can. J. Bot. 82:1768-1775.

Angle, J., Dunn, K., and Wagner, G. 1982. Effect of cultural practices on the soil population of Aspergillus flavus and Aspergillus parasiticus. Soil Sci. Soc. Am. J. 46:301-304.

Atehnkeng, J., Ojiambo, P., Ikotun, T., Sikora, R., Cotty, P., and Bandyopadhyay, R. 2008. Evaluation of atoxigenic isolates of Aspergillus flavus as potential biocontrol agents for aflatoxin in maize. Food Addit. Contam. 25: 1264-1271.

Bayman, P., Baker, J. L., and Mahoney, N. E. 2002. Aspergillus on tree nuts: Incidence and associations. Mycopathologia 155:161-169.

Bayman, P., and Cotty, P. J. 1991. Vegetative compatibility and genetic diversity in the Aspergillus flavus population of a single field. Can. J. Bot. 69:1707-1711.

Bayman, P., and Cotty, P. J. 1993. Genetic diversity in Aspergillus flavus: Association with aflatoxin production and morphology. Can. J. Bot. 71:23-31.

Benjamini, Y., and Hochberg, Y. 1995. Controlling the false discovery rate: A practical and powerful approach to multiple testing. J. R. Stat. Soc. Ser. B (Methodol.) 57:289-300.

Bigelow, D., Orum, T., Cotty, P., and Nelson, M. 2000. Monitoring Aspergillus flavus AF36 and S strain incidence in the Desert Southwest. In: 2000 APS Pacific Division Meeting Abstracts (joint with Canadian Phytopathological Society), Victoria, BC, Canada.

CA-ABC (California Almonds Almond Board of California). 2013. 2013 Almond Almanac. Online publication. http://www.almondboard.com/AboutTheAlmondBoard/ Documents/2013\%20Almanac\%20-\%20Final.pdf.

Cardwell, K., and Cotty, P. 2002. Distribution of Aspergillus section Flavi among field soils from the four agroecological zones of the Republic of Benin, West Africa. Plant Dis. 86:434-439.

CAST (Council for Agricultural Science and Technology). 2003. Mycotoxins: Risks in plant, animal, and human systems. Task Force Rep. 139. Online publication. http://www.trilogylab.com/uploads/Mycotoxin_CAST_Report.pdf.

CDWR (California Department of Water Resources). 2010. California's Drought of 2007-2009, An Overview. September 2010. Online publication. http://www.water.ca.gov/waterconditions/drought/docs/DroughtReport2010. pdf.

CIMIS (California Irrigation Management Information System). 2011. Monthly report. Online publication. http://wwwcimis.water.ca.gov.

Cotty, P. J., Bayman, P., Egel, D., and Elias, K. 1994. Agriculture, aflatoxins and Aspergillus. Pages 1-27 in: The Genus Aspergillus: From taxonomy and genetics to industrial application. K. A. Powell, A. Renwick, and J. F. Peberdy, eds. Plenum Press, New York.

Cotty, P. J. 1989. Virulence and cultural characteristics of two Aspergillus flavus strains pathogenic on cotton. Phytopathology 79:808-814.

Cotty, P. J. 1994a. Comparison of four media for the isolation of Aspergillus flavus group fungi. Mycopathologia 125:157-162.

Cotty, P. J. 1994b. Influence of field application of an atoxigenic strain of Aspergillus flavus on the populations of A. flavus infecting cotton bolls and on the aflatoxin content of cottonseed. Phytopathology 84:1270-1277.

Cotty, P. J. 1997. Aflatoxin-producing potential of communities of Aspergillus section Flavi from cotton producing areas in the United States. Mycol. Res. 101:698-704.

Cotty, P. J., Antilla, L., and Wakelyn, P. J. 2007. Competitive exclusion of aflatoxin producers: Farmer driven research and development. Pages 241-253 in: Biological Control: A Global Perspective. C. Vincent, M. Goettel, and G. Lazarovits, eds. CAB International, Oxfordshire, UK.

Cotty, P. J., and Cardwell, K. F. 1999. Divergence of West African and North American communities of Aspergillus section Flavi. Appl. Environ. Microbiol. 65:2264-2266.

Cotty, P. J., and Jaime-Garcia, R. 2007. Influences of climate on aflatoxin producing fungi and aflatoxin contamination. Int. J. Food Microbiol. 119:109-115.

Diener, U. L., Cole, R. J., Sanders, T., Payne, G. A., Lee, L. S., and Klich, M. A. 1987. Epidemiology of aflatoxin formation by Aspergillus flavus*. Annu. Rev. Phytopathol. 25:249-270.

Donner, M., Atehnkeng, J., Sikora, R. A., Bandyopadhyay, R., and Cotty, P. J. 2009. Distribution of Aspergillus section Flavi in soils of maize fields in three agroecological zones of Nigeria. Soil Biol. Biochem. 41:37-44.

Dorner, J. W., Cole, R. J., Connick, W. J., Daigle, D. J., Mcguire, M. R., and Shasha, B. S. 2003. Evaluation of biological control formulations to reduce aflatoxin contamination in peanuts. Biol. Control 26:318-324.
Doster, M. A., Cotty, P. J., and Michailides, T. J. 2014. Evaluation of the atoxigenic Aspergillus flavus strain AF36 in pistachio orchards. Plant Dis. 98:948-956.

Doster, M. A., and Michailides, T. J. 1994a. Aspergillus molds and aflatoxins in pistachio nuts in California. Phytopathology 84:583-590.

Doster, M. A., and Michailides, T. J. 1994b. Development of Aspergillus molds in litter from pistachio trees. Plant Dis. 78:393-397.

Doster, M. A., Michailides, T. J., and Morgan, D. P. 1996. Aspergillus species and mycotoxins in figs from California orchards. Plant Dis. 80:484-489.

EU (European Union). 2010. Commission Regulation (EU) No 165/2010 of 26 February 2010 amending Regulation (EC) No 1881/2006 setting maximum levels for certain contaminants in foodstuffs as regards aflatoxins. Official J. Eur. Union 2010:8-12. Online: http://faolex.fao.org/docs/pdf/eur92874. pdf.

FDA (Food and Drug Administration). 1996. Compliance Policy Guides Manual. Sec.555.400, 268, Sec. 570.500, 299.

Horn, B. W. 2007. Biodiversity of Aspergillus section Flavi in the United States: A review. Food Addit. Contam. 24:1088-1101.

Horn, B. W., and Dorner, J. W. 1998. Soil populations of Aspergillus species from section Flavi along a transect through peanut-growing regions of the United States. Mycologia 90:767-776.

Horn, B. W., and Dorner, J. W. 1999. Regional differences in production of aflatoxin B1 and cyclopiazonic acid by soil isolates of Aspergillus flavus along a transect within the United States. Appl. Environ. Microbiol. 65: 1444-1449.

Horn, B. W., and Dorner, J. W. 2009. Effect of nontoxigenic Aspergillus flavus and A. parasiticus on aflatoxin contamination of wounded peanut seeds inoculated with agricultural soil containing natural fungal populations. Biocontrol Sci. Technol. 19:249-262.

Horn, B. W., Greene, R. L., and Dorner, J. W. 1995. Effect of corn and peanut cultivation on soil populations of Aspergillus flavus and A. parasiticus in southwestern Georgia. Appl. Environ. Microbiol. 61:2472-2475.

Horn, B. W., Greene, R. L., Sobolev, V. S., Dorner, J. W., Powell, J. H., and Layton, R. C. 1996. Association of morphology and mycotoxin production with vegetative compatibility groups in Aspergillus flavus, A. parasiticus, and A. tamarii. Mycologia 88:574-587.

Jaime-Garcia, R., and Cotty, P. J. 2004. Aspergillus flavus in soils and corncobs in south Texas: Implications for management of aflatoxins in corn-cotton rotations. Plant Dis. 88:1366-1371.

Jaime-Garcia, R., and Cotty, P. J. 2006. Spatial relationships of soil texture and crop rotation to Aspergillus flavus community structure in South Texas. Phytopathology 96:599-607.

Jaime-Garcia, R., and Cotty, P. J. 2010. Crop rotation and soil temperature influence the community structure of Aspergillus flavus in soil. Soil Biol. Biochem. 42:1842-1847.

Joffe, A. 1969. Aflatoxin produced by 1,626 isolates of Aspergillus flavus from groundnut kernels and soils in Israel. Nature 221:492.

KAC (Kearney Agricultural Research and Extension Center). 2012. Soils to Go Web-Based GIS. Geographic Information Systems Facility, University of California, Division of Agriculture and Natural Resources. Online publication. http://kare.ucanr.edu/programs/GIS_facility.

Klich, M. A. 2007. Aspergillus flavus: The major producer of aflatoxin. Mol. Plant Pathol. 8:713-722.

Klich, M. A., and Pitt, J. I. 1988. Differentiation of Aspergillus flavus from A. parasiticus and other closely related species. Trans. Br. Mycol. Soc. 91:99-108.

Laird, N. M., and Ware, J. H. 1982. Random-effects models for longitudinal data. Biometrics 38:963-974.

Lisker, N., Michaeli, R., and Frank, Z. 1993. Mycotoxigenic potential of Aspergillus flavus strains isolated from groundnuts growing in Israel Mycopathologia 122:177-183.

Mahoney, N. E., and Rodriguez, S. B. 1996. Aflatoxin variability in pistachios Appl. Environ. Microbiol. 62:1197-1202.

Mateles, R., and Adye, J. 1965. Production of aflatoxins in submerged culture. Appl. Microbiol. 13:208-211.

Molyneux, R. J., Mahoney, N., Kim, J. H., and Campbell, B. C. 2007. Mycotoxins in edible tree nuts. Int. J. Food Microbiol. 119:72-78.

Nelder, J. A., and Baker, R. 1972. Generalized linear models. J. R. Stat. Soc. (Ser. A) $135: 370-384$

Orum, T. V., Bigelow, D. M., Cotty, P. J., and Nelson, M. R. 1999. Using predictions based on geostatistics to monitor trends in Aspergillus flavus strain composition. Phytopathology 89:761-769.

Orum, T. V., Bigelow, D. M., Nelson, M. R., Howell, D. R., and Cotty, P. J. 1997. Spatial and temporal patterns of Aspergillus flavus strain composition and propagule density in Yuma County, Arizona, soils. Plant Dis. 81:911-916.

Pitt, J., Hocking, A. D., and Glenn, D. R. 1983. An improved medium for the detection of Aspergillus flavus and A. parasiticus. J. Appl. Bacteriol. 54: 109-114.

Probst, C., Schulthess, F., and Cotty, P. 2010. Impact of Aspergillus section Flavi community structure on the development of lethal levels of aflatoxins in Kenyan maize (Zea mays). J. Appl. Microbiol. 108:600-610.

Purcell, S. L., Phillips, D., and Mackey, B. E. 1980. Distribution of Aspergillus flavus and other fungi in several almond-growing areas of California. Phytopathology 70:926-929. 
Razzaghi-Abyaneh, M., Shams-Ghahfarokhi, M., Allameh, A., Kazeroon-Shiri, A., Ranjbar-Bahadori, S., Mirzahoseini, H., and Rezaee, M.-B. 2006. A survey on distribution of Aspergillus section Flavi in corn field soils in Iran: Population patterns based on aflatoxins, cyclopiazonic acid and sclerotia production. Mycopathologia 161:183-192.

Schroeder, H., and Boller, R. 1973. Aflatoxin production of species and strains of the Aspergillus flavus group isolated from field crops. Appl. Microbiol. 25: 885-889.

USDA-NASS (United States Department of Agriculture National Agricultural Statistic Service). 2011. 2011 California Almond Forecast. Online publication. http://www.nass.usda.gov/Statistics_by_State/California/Publications/ Fruits_and_Nuts/201105almpd.pdf.
USDA-NRCS (United States Department of Agriculture Natural Resources Conservation Service). 2011. Web Soil Survey. Online publication. http:// websoilsurvey.nrcs.usda.gov.

Vaamonde, G., Patriarca, A., Fernández Pinto, V., Comerio, R., and Degrossi, C. 2003. Variability of aflatoxin and cyclopiazonic acid production by Aspergillus section Flavi from different substrates in Argentina. Int. J. Food Microbiol. 88 79-84.

Van Egmond, H. P., Schothorst, R. C., and Jonker, M. A. 2007. Regulations relating to mycotoxins in food. Anal. Bioanal. Chem. 389:147-157.

Zablotowicz, R., Abbas, H., and Locke, M. 2007. Population ecology of Aspergillus flavus associated with Mississippi Delta soils. Food Addit. Contam. 24:1102-1108. 